\title{
An Intelligent Feedback Controller Design for Energy Efficient Air Conditioning System
}

\author{
P. Hengjinda, \\ Department of Industrial Robotics and Automation System, \\ Phetchaburi Rajabhat University, \\ Phetchaburi, Thailand. \\ Dr. Joy Iong Zong Chen, \\ Professor, Department of Electrical Engineering, \\ Da-Yeh University, \\ Taiwan. \\ Email id: jchen@mail.dyu.edu.tw
}

\begin{abstract}
Air conditioning systems were invented to improve human comfort in a room or hall. An efficient air conditioner systems are always needed to minimize the power consumption. There are several settings with lot of control devices were introduced in the past years to achieve minimal energy consumption rate. Those control systems were minimized the energy consumption to certain limit without considering human comfort. The proposed model is designed to minimize the energy consumption with maximum human comfort. Several sensor modules were introduced in the model to predict human comfort level in a room or hall. The sensor data are taken as feedback to the air conditioning system for attaining maximum human comfort level. The proposed design is verified with energy consumption calculation and change in room temperature measurements.
\end{abstract}

Keywords: Intelligent controller, feedback sensors, air conditioning system control.

\section{Introduction}

The general air conditioning system is a closed loop system which operates with respect to the given temperature by a user. The room temperature is always monitored by an air conditioner system to maintain the room temperature with the desired input temperature. The desired temperature can be changed at any time with user preference. The change in input temperature can be given to the air conditioner system through wire lined switches, infrared remote or mobile device. Figure 1 indicates a block diagram of a general air conditioning system. Apart from temperature control, certain latest air conditioning units are structured with timing and moisture control. All these kind of add-on convenience are provided with the help of different sensor modules. These kind of features makes the system price to reach certain extent.

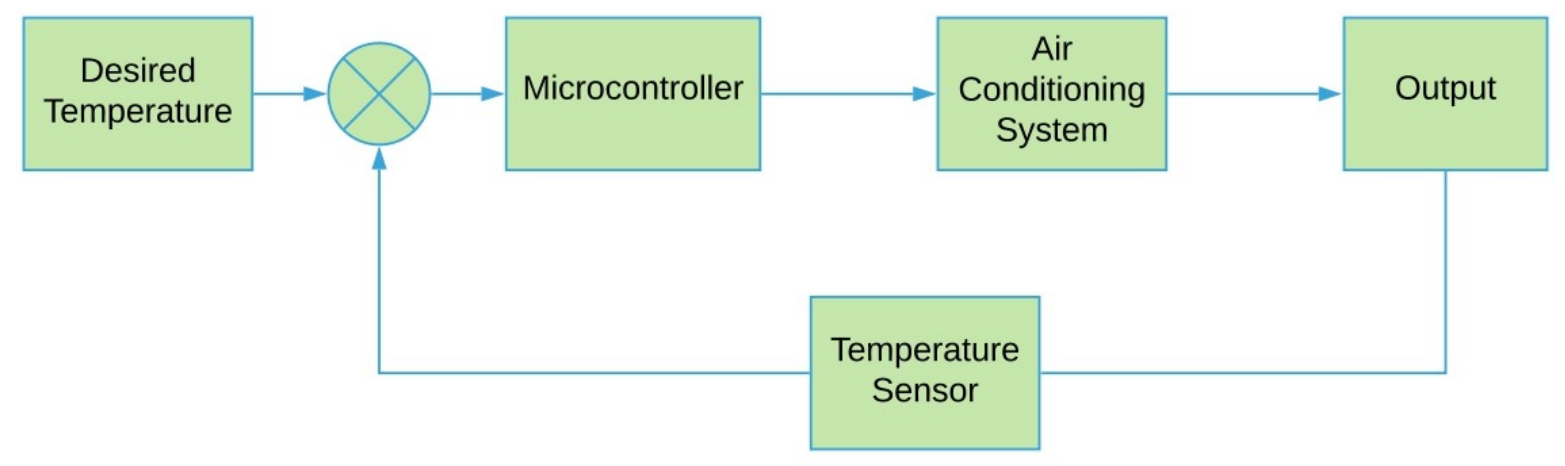

Figure 1. Block diagram components of general air conditioner.

ISSN: 2582-3825 (online)

Submitted: 22.06 .2020

Accepted: 08.07.2020

Published: 17.07.2020 
Journal of Electronics and Informatics (2020)

Vol.02/ No.03

Pages: 168-174

http://www.irojournals.com/iroei/

DOI: https://doi.org/10.36548/jei.2020.3.003

The major constraint in running an air conditioning system for longer hour is energy cost. The general air conditioning systems are made to meet the user satisfaction on their body comfort alone. The proposed intelligent control system is developed to meet a user's body comfort along with energy minimization process.

\section{Related work}

A system for maintaining the air quality in a closed room with fresh outdoor air system [1] was proposed to give better breathing comfort. The proposed model is also designed to achieve a good energy efficiency by nixing of fresh air with indoor air. An automation system with different sensors [2] was implemented to monitor various parameters from a field. In similar to that way any automation system can be made with more number of sensors for visualizing different parameters in a room. A room air conditioning performance was analyzed [3] with liquid suction heat exchanger for improving the energy efficiency. The heat exchanger setup was fitted with R290 to determine the refrigeration effect for power consumption calculation. An air conditioning leakage detection system [4] was developed to improve user comfort and quality of an air in a moving vehicle. A MATLAB simulation was performed to verify this model in terms of leakage detection and recognition. A microcontroller based air conditioning system was designed to control on/off condition in a vehicle [5]. The system is employed with an arduino controller for maintaining the temperature condition of air conditioner unit to improve its efficiency.

A sensing and control strategy based on robotic arm [6] was designed to operate pick and place process with less energy consumption. The response time of the signal given is tuned with very lesser time to achieve proper output. An embedded ventilation air conditioning system [7] was developed to control the room atmosphere at several riskier condition. The proposed model is equipped with ventilation fans for extracting unwanted smokes from the room. The same setup is used for ventilating the room with fresh air from the surroundings. The model is employed with a temperature sensor for making alarm signals at certain critical conditions. A neural network based power management system [8] was designed to monitor the weather conditions around a street light for modifying its intensity. The system is helpful in saving the energy by minimizing the supply power at unwanted conditions. A 12 channel temperature acquisition system [9] was structured to monitor the temperature changes on fluid and working wall temperature. The system is connected with an arduino mega microcontroller for measuring the temperature for analysis purpose. The temperature sensors are connected to the microcontroller through MAX6675 interfacing unit. An energy saving system at parking areas [10] was framed by modifying the operation conditions of the lights fixed in such areas. The location is continuously monitored with help of a sensor device connected through a microcontroller unit. The place get more lumens of light when there is a human movement. The lumens is reduced to certain limit at normal conditions. This achieved reduced power consumption in the parking area lights.

An arduino based data acquisition system [11] was proposed to monitor indoor environmental quality of a room. The system is fixed with several sensors for continuous monitoring purpose. Temperature, carbon, humidity, luminance are measured in these system but the sensors are connected with separate microcontrollers. The microcontrollers are transmitting the observed signal through wireless communication for recording and analyzing purpose. A smart security system [12] was designed to monitor suspicious activity in certain volatile areas. The system is employed with motion sensor for identifying human movement in some particular locations. An air quality measurement system [13] using arduino controller was developed to monitor outdoor air quality. The system is connected with four different sensors for measuring four different kinds of pollution measures. An IoT based air conditioner control system [14] was designed to control from an android application. The android application is connected with a blynk cloud unit for data sharing to the microcontroller through ESP8266 device module. The microcontroller controls the air conditioner and several electrical appliances connected with the microcontroller with respect to the received signals. An on/off control system based on arduino microcontroller [15] was planned to operate the air conditioner unit at some specific temperature. Here the microcontroller is connected with sensor and relay unit making such operations.

\section{Proposed Method}

The proposed intelligent controller for air conditioning system is developed by altering certain features in the existing air conditioning system with an arduino microcontroller. The main motive of this work is to minimize the electricity expenses with maximum human comfort. Figure 2 indicates the block diagram of the proposed intelligent control system. It is equipped with two numbers of temperature sensors connected with microcontroller. One is fixed

ISSN: 2582-3825 (online)

Submitted: 22.06.2020

Accepted: 08.07.2020

Published: 17.07.2020 
Journal of Electronics and Informatics (2020)

Vol.02/ No.03

Pages: 168-174

http://www.irojournals.com/iroei/

DOI: https://doi.org/10.36548/jei.2020.3.003

at the room along with the air conditioning system and another at window side of the room for measuring surrounding temperature. The window in the room is altered to open and close with motor controlled devices. The motors involved for doing such operation is connected with the microcontroller through a relay module.

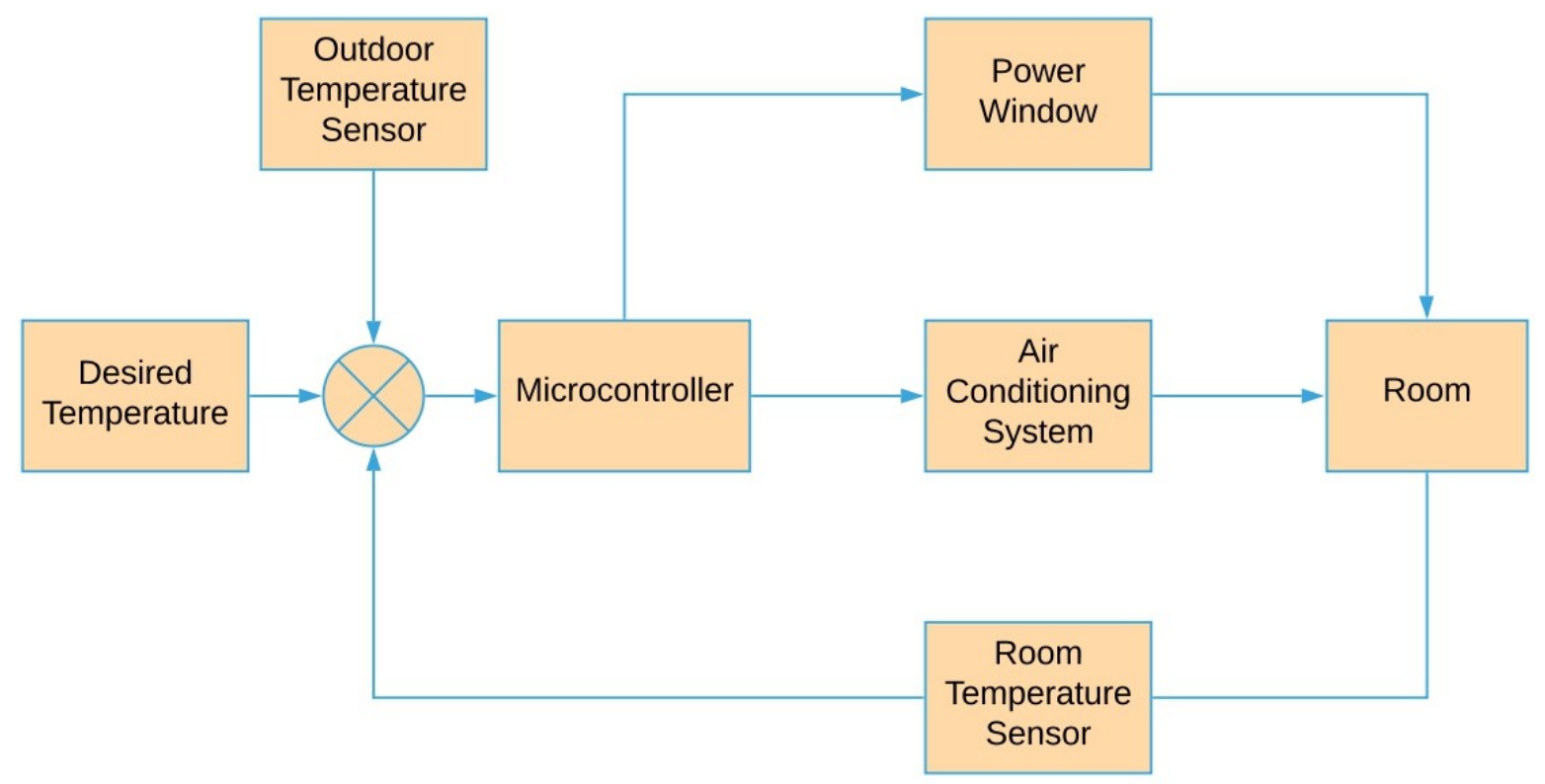

Figure 2. Block diagram of the proposed intelligent controller.

The operation of the proposed intelligent controller is represented in figure 3 as flow chart for better understanding. The microcontroller fixed in the circuit gets power along with air conditioner unit for initializing the sensors and window control circuits. After few seconds the microcontroller reads the desired input temperature given by the user and compare it with the readings observed from room temperature sensor and outdoor temperature sensor.

The temperatures are measured with LM35 sensors and the operations according desired temperature and measured temperature is coded to the microcontroller. The general air conditioner units are not coupled with room windows for such intelligent operations. The usual air conditioner operation is engaged with the room temperature and desired temperature alone. So once the temperature is given, the usual model works till the room achieves certain temperature. After that the air conditioner will go to sleep mode for some time to maintain the temperature. It does not care about the outdoor temperature of the room. The proposed intelligent controller continuously monitors the surrounding temperature and opens the window when the surrounding temperatures are equal to the room temperature.

During winter season the desired temperature may become higher than the surrounding temperature in the late night. At that time the proposed intelligent controller stops air conditioner unit and close the window for ensuring human comfortness. The general air conditioner units never care about such conditions and make the people to feel uncomfortable in such conditions while they are in sleep. The proposed model maintains the desired temperature to its maximum than the existing model air conditioners. The proposed model is also reduces the energy consumption to certain extent.

ISSN: 2582-3825 (online)

Submitted: 22.06.2020

Accepted: 08.07.2020

Published: 17.07.2020 
Journal of Electronics and Informatics (2020)

Vol.02/ No.03

Pages: 168-174

http://www.irojournals.com/iroei/

DOI: https://doi.org/10.36548/jei.2020.3.003

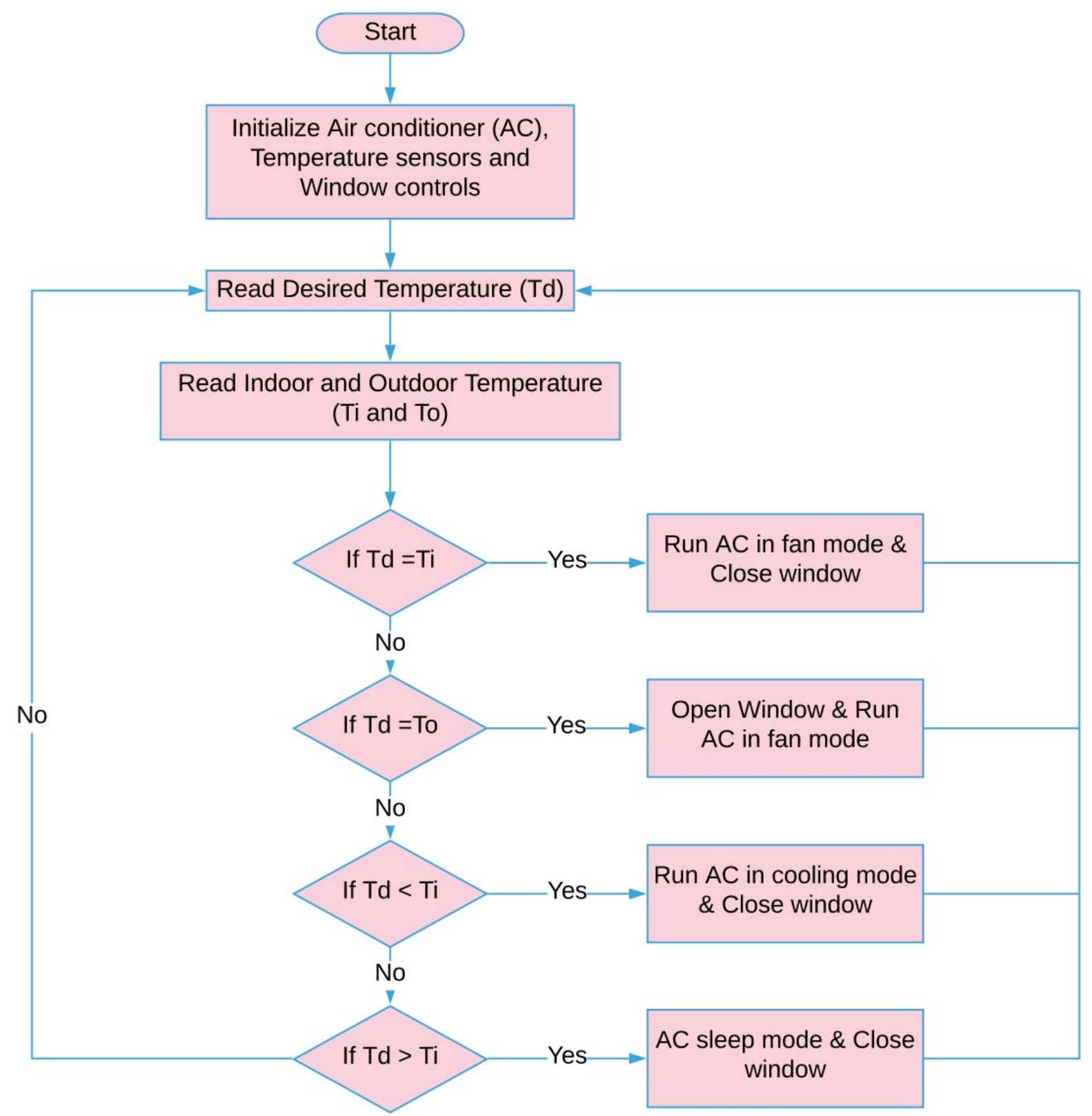

Figure 3. Flow chart of the proposed intelligent controller system.

\section{Experimental Results}

The proposed model is verified with one ton air conditioning unit of 3504Watts for continuous 8 hour operation in the night. Figure 4 explores the temperature maintained in the room with desired input temperature of

ISSN: 2582-3825 (online) 
Journal of Electronics and Informatics (2020)

Vol.02/ No.03

Pages: 168-174

http://www.irojournals.com/iroei/

DOI: https://doi.org/10.36548/jei.2020.3.003

$28^{\circ} \mathrm{Celsius}$ with existing model air conditioner and proposed model air conditioner. Same wattage of air conditioners were kept to nearby rooms of same size for this process. The temperature readings were taken by the microcontroller with serial monitor application of arduino program. The temperature of outdoor and indoor room were measured hourly once for tabulating the graph shown in figure 4 . This shows how the proposed model improves the comfort level of a human inside a room by maintaining the desired temperature.

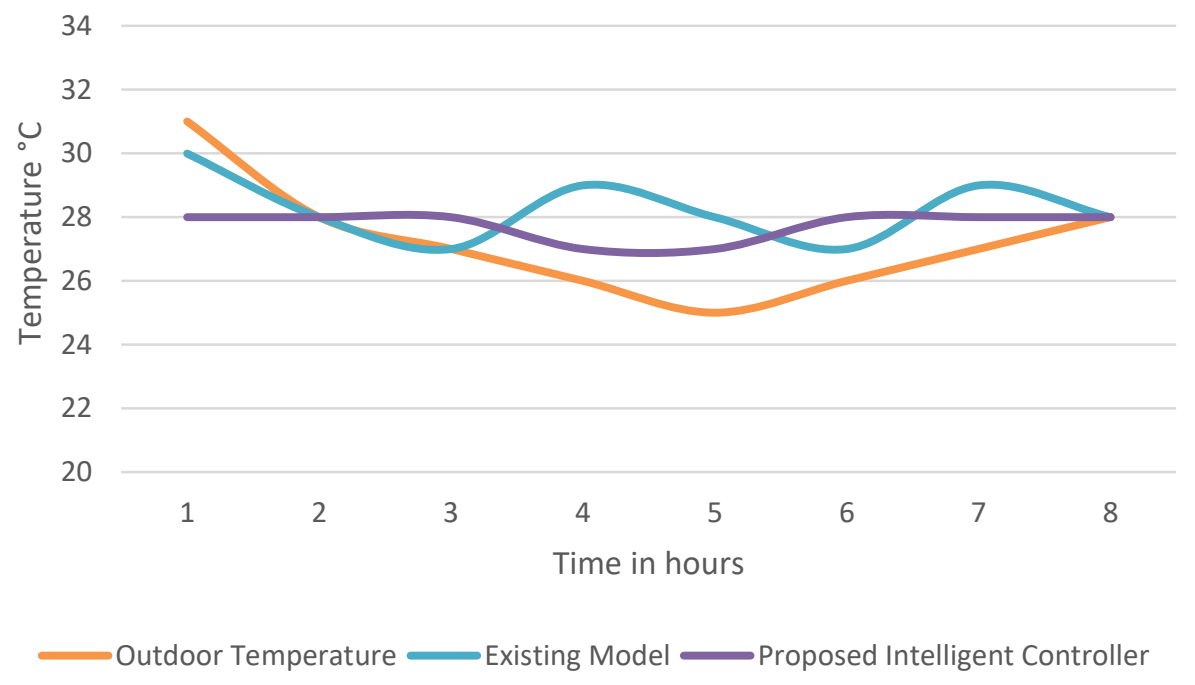

Figure 4. Comparison of proposed intelligent controller comfort with existing models.

The proposed model energy consumption can be calculated by its mode of operation figured in figure 5(a) and 5(b). Figure 5(a) shows the operation of existing model. Where, 0 is meant for "OFF" condition and 1 is meant for "ON" condition. The working condition of the proposed model is comparatively lesser than the existing model. Hence it reduces power consumption to its maximum.

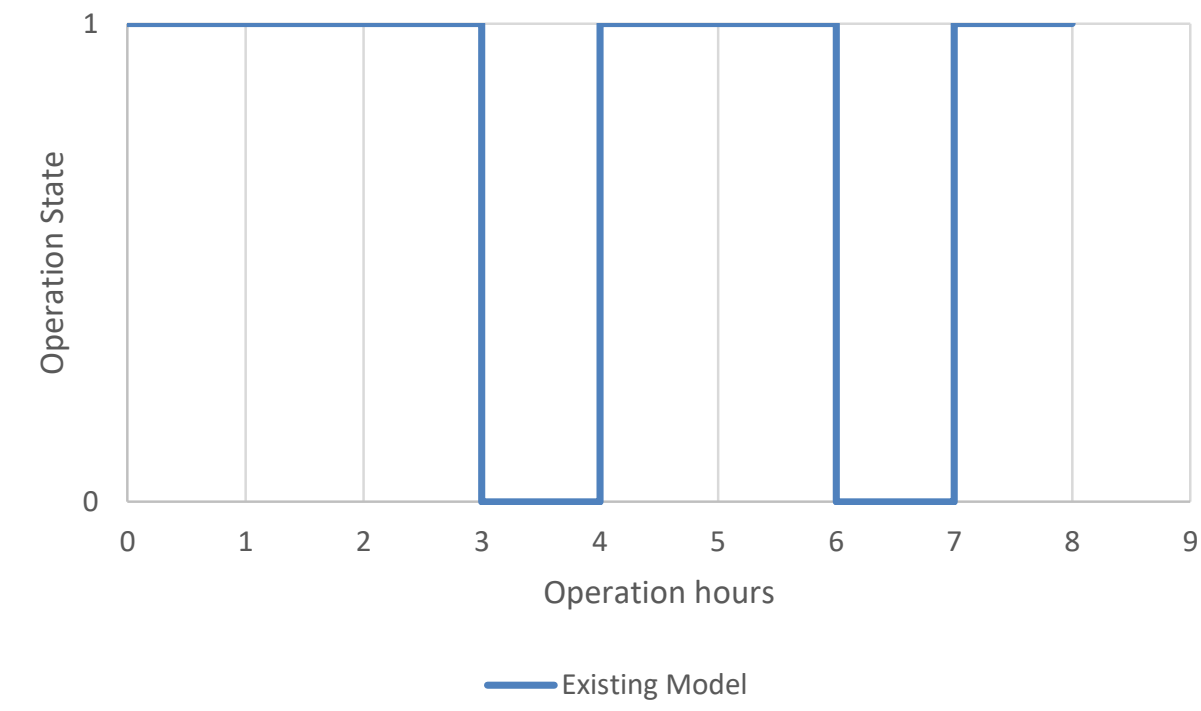

Figure 5(a). Operation state of existing model.

ISSN: 2582-3825 (online)

Submitted: 22.06.2020

Accepted: 08.07.2020

Published: 17.07.2020 
Journal of Electronics and Informatics (2020)

Vol.02/ No.03

Pages: 168-174

http://www.irojournals.com/iroei/

DOI: https://doi.org/10.36548/jei.2020.3.003

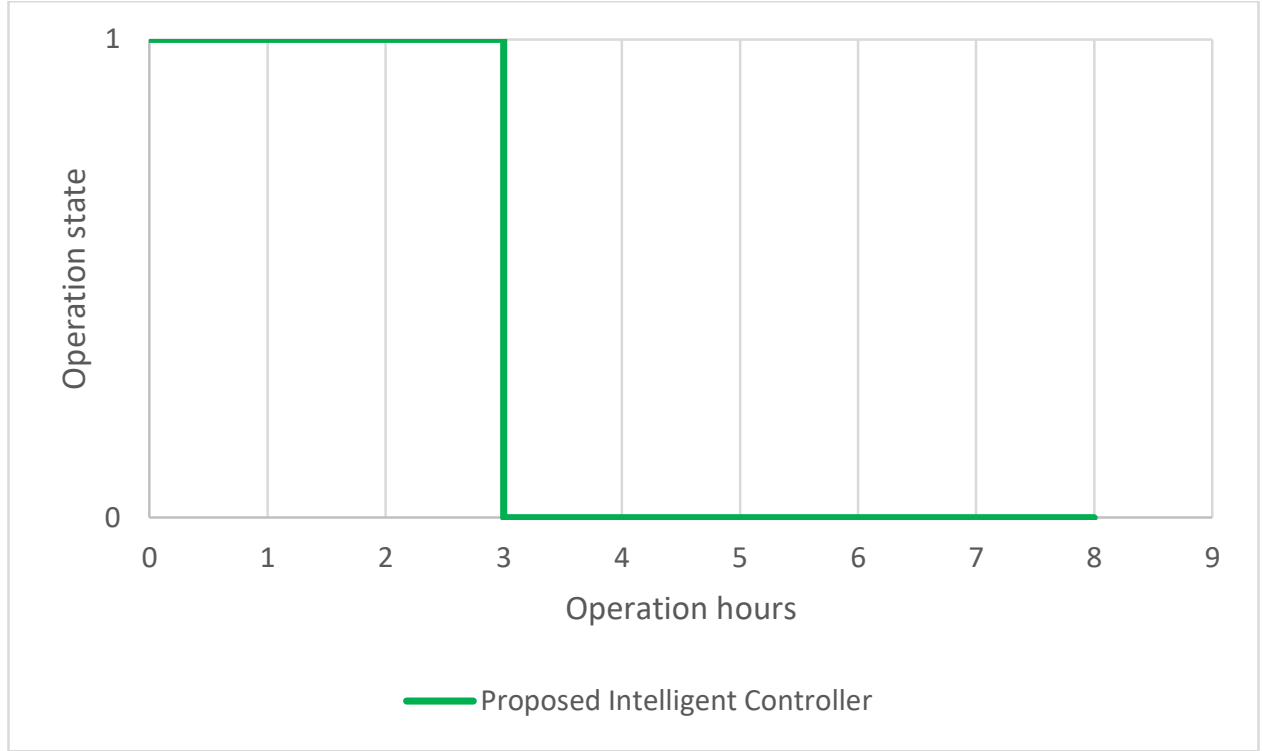

Figure 5(b). Operation state of proposed model.

\section{Conclusion}

The proposed intelligent controller controls the air conditioning unit with respect to the environment temperature. The environment temperature is measured with a separate sensor connected at the window side of a room. The energy consumption is minimized by allowing the outdoor fresh air to come inside a room when the desired temperature and environment temperatures are equal. This reduces the operation time of the air conditioner unit. The comfort level also improved in the proposed model by maintaining the desired temperature for longer hours. The comfort level is measured by analyzing the constant level temperature of the room and the energy consumption is analyzed by plotting the working time of the air conditioning unit.

\section{References}

1. Cheng, Yong, Sheng Zhang, Chao Huan, Majeed Olaide Oladokun, and Zhang Lin. "Optimization on fresh outdoor air ratio of air conditioning system with stratum ventilation for both targeted indoor air quality and maximal energy saving." Building and Environment 147 (2019): 11-22.

2. Raj, Jennifer S., and J. Vijitha Ananthi. "Automation using IoT in greenhouse environment." Journal of Information Technology 1, no. 01 (2019): 38-47.

3. Nasution, Dian Morfi, Muhammad Idris, and Nugroho Agung Pambudi. "Room air conditioning performance using liquid-suction heat exchanger retrofitted with R290." Case Studies in Thermal Engineering 13 (2019): 100350 .

4. Manoharan, Samuel. "Image Detection Classification and Recognition for Leak Detection in Automobiles." Journal of Innovative Image Processing (JIIP) 1, no. 02 (2019): 61-70.

5. Shah, Hiren, Aftab Maniar, Kushal Tailor, Dhruv Patel, and Harsh Patel. "An Arduino Micro-controller Operated Automobile Air Conditioning System." In Advances in Interdisciplinary Engineering, pp. 263-275. Springer, Singapore, 2019.

6. $\quad$ Smys, S., and G. Ranganathan. "Robot assisted sensing control and manufacture in automobile industry." J ISMAC 1, no. 03 (2019): 180-187.

7. Awawdeh, Moath, Anees Bashir, Tarig Faisal, Khawla Alhammadi, Mouza Almansori, and Sara Almazrouei. "Embedded Ventilation Air Conditioning System for Protection Purposes with IoT Control." In 2019 Advances in Science and Engineering Technology International Conferences (ASET), pp. 1-6. IEEE, 2019.

8. Smys, S., Abul Basar, and Haoxiang Wang. "Artificial Neural Network Based Power Management for Smart Street Lighting Systems." Journal of Artificial Intelligence 2, no. 01 (2020): 42-52.

ISSN: 2582-3825 (online)

Submitted: 22.06.2020

Accepted: 08.07.2020

Published: 17.07.2020 
Journal of Electronics and Informatics (2020)

Vol.02/ No.03

Pages: 168-174

http://www.irojournals.com/iroei/

DOI: https://doi.org/10.36548/jei.2020.3.003

9. Nalavade, Sandeep P., Abhishek D. Patange, Chandrakant L. Prabhune, Sharad S. Mulik, and Mahesh S. Shewale. "Development of 12 Channel Temperature Acquisition System for Heat Exchanger Using MAX6675 and Arduino Interface." In Innovative Design, Analysis and Development Practices in Aerospace and Automotive Engineering (I-DAD 2018), pp. 119-125. Springer, Singapore, 2019.

10. Sungheetha, Akey, and Rajesh Sharma. "Cost Effective Energy-Saving System in Parking Spots." Journal of Electronics 2, no. 01 (2020): 18-29.

11. Karami, Majid, Gabrielle Viola McMorrow, and Liping Wang. "Continuous monitoring of indoor environmental quality using an Arduino-based data acquisition system." Journal of Building Engineering 19 (2018): 412-419.

12. Chen, Joy Iong Zong. "Smart Security System for Suspicious Activity Detection in Volatile Areas." Journal of Information Technology 2, no. 01 (2020): 64-72.

13. Gunawan, Teddy Surya, Yasmin Mahira Saiful Munir, Mira Kartiwi, and Hasmah Mansor. "Design and implementation of portable outdoor air quality measurement systemn using arduino." International Journal of Electrical and Computer Engineering 8, no. 1 (2018): 280.

14. Taştan, Mehmet, and Hayrettin Gökozan. "An Internet of Things based air conditioning and lighting control system for smart home." American Scientific Research Journal for Engineering, Technology, and Sciences (ASRJETS) 50, no. 1 (2018): 181-189.

15. Erham, E., Markus Markus, and W. P. Sopianti. "Design of a new on-off controller based on Arduino UNO R3 with application to Window A/C." IPTEK Journal of Proceedings Series 3 (2018): 174-182.

ISSN: 2582-3825 (online)

Submitted: 22.06 .2020

Accepted: 08.07.2020

Published: 17.07.2020 